\section{Instalación del seminario de biodiversidad y especies amenazadas (Ambientes urbanos)}

\author{
Autor: \\ Dagoberto Arrieta Prieto' \\ ${ }^{1}$ Vicepresidente, Capítulo Bucaramanga, ACCB, Período 2017, \\ darrietadap@gmail.com.
}

DOI:

http://dx.doi.org/10.15649/2346075X.470

Colombia es uno de los países con mayor biodiversidad del planeta; ostentamos el primer lugar en el número de especies de aves; el segundo lugar en especies de plantas y anfibios; el tercero en especies de reptiles y el quinto en especies de mamíferos. Esta amplia biodiversidad ha permitido que seamos poseedores de numerosas especies endémicas.

Esta inmensa riqueza de fauna y flora se ha sustentado en las variaciones topográficas del territorio nacional, en la extensa hidrografía y en los ambientes marinos de las costas caribe y pacífica. Contamos con todos los pisos térmicos desde el nivel del mar hasta las nieves perpetuas y poseemos la mitad de los páramos del mundo.

No obstante, lo anterior, la mayoría de especies se encuentran muy amenazadas debido fundamentalmente a la pérdida y fragmentación de los ecosistemas, así como a la sobreexplotación de los recursos ecosistémicos. Hace algunos años la fundación Proaves informó que el $80 \%$ de las especies de aves del territorio nacional se encuentra en algún grado de peligro. No se puede esperar otra cosa en un país con una de las mayores tasas de deforestación en el mundo, en particular los ecosistemas andinos, los bosques de la región Caribe y la selva amazónica. A esto se suma la pérdida de humedales; en mayo de 2012 el Centro Francés de Investigaciones informó que Colombia, Venezuela, Bolivia, Brasil y Paraguay son los países de Suramérica en donde más se han perdido humedales.

Es evidente: el futuro es incierto en los ambientes naturales. A la pérdida y fragmentación de los ecosistemas se suma el alto grado de contaminación química y biológica. Las especies animales y vegetales se tornan muy vulnerables,

\section{EDITORIAL}

no cuentan con las dimensiones adecuadas para mantener el tamaño poblacional y, lo que es peor, no disponen de suficiente alimento, ni del alimento que les ha suministrado la naturaleza. No tienen otra alternativa: invadir los ambientes urbanos y tratar de sobrevivir en medios de condiciones extremas.

Corresponde entonces a académicos y científicos orientar su conocimiento hacia esas especies que hoy tratan de sobrevivir en nuestras avenidas, antejardines de viviendas $y$ en cualquier espacio urbano que les sirva de protección. La investigación con estas especies debe contribuir a salvaguardar la supervivencia de las mismas. Esa es la razón de este encuentro.

La ACCB, capítulo Bucaramanga, presenta una cordial bienvenida a todos los participantes y sinceros agradecimientos a las entidades patrocinadoras. Nos honran con su presencia. 